\title{
К РАСЧЛЕНЕНИЮ ОРДОВИКСКИХ ОТЛОЖЕНИЙ НА ЛЕНИНГРАДСКОМ МЕСТОРОЖДЕНИИ ГОРЮЧИХ СЛАНЦЕВ
}

В Прибалтийском сланцевом бассейне при геологической съемке и геологоразведочных работах применяются унифицированные региональные стратиграфические схемы. Для расчленения отложений ордовика Эстонского месторождения горючих сланцев используется унифицированная стратиграфическая схема Прибалтики (Решения..., 1978). На Ленинградском месторождении оно проводится в соответствии со схемой, принятой в I томе «Геологии СССР» (Селиванова, 1971). К тому, что в пределах единого бассейна осадко- и сланценакопления до сих пор применяются разные, значительно отличающиеся друг от друга стратиграфические схемы, привели различное толкование литологических и палеонтологических критериев эстонскими и ленинградскими исследователями и территориальная принадлежность упомянутых месторождений.

Палеонтологическая изученность ордовикских отложений в бассейне весьма неравномерна. Детальное изучение этих отложений проводилось по стратотипическим обнажениям на территории ЭССР и в меньшей мере по разрезам опорных скважин. Изучение макрофауны опорных скважин на Ленинградском месторождении, проводившееся при крупномасштабной комплексной геологической съемке, не обеспечило достаточно четкого фаунистически обоснованного расчленения карбонатной толщи ордовика. Причиной тому послужила ее малочисленность и плохая сохранность. Поэтому расчленение и сопоставление разрезов отложений ордовика геологоразведочных скважин осуществляется в основном по макролитологическим признакам (чечевичные слоя, слои горючих сланцев, пиритизированные поверхности перерывов, прослои метабентонитов).

Согласно принятым стратиграфическим схемам, на Ленинградском месторождении для расчленения отложений ордовика используются иные уровни, чем на Эстонском. Особенно хорошо это показано в статье Р. М. Мянниля (1963), где сопоставлены разрезы скважин № 465 и 1146. Расчленение первого из них проводилось по ленинградской, расчленение второго - по эстонской схеме. В результате было установлено существенное различие в границах и объемах почти всех среднеордовикских горизонтов.

Ввиду вышеизложенного, для выяснения строения и геологической истории развития бассейна необходимо точное и обоснованное установление границ и объемов стратиграфических подразделений обоих регионов с привлечением палеонтологических данных.

Для палеонтологически обоснованного расчленения ордовикских отложений Ленинградского месторождения была сделана попытка использовать микрофауну - остракоды, которые достаточно хорошо изучены на Эстонском месторождении. Остракоды из разреза скв. 

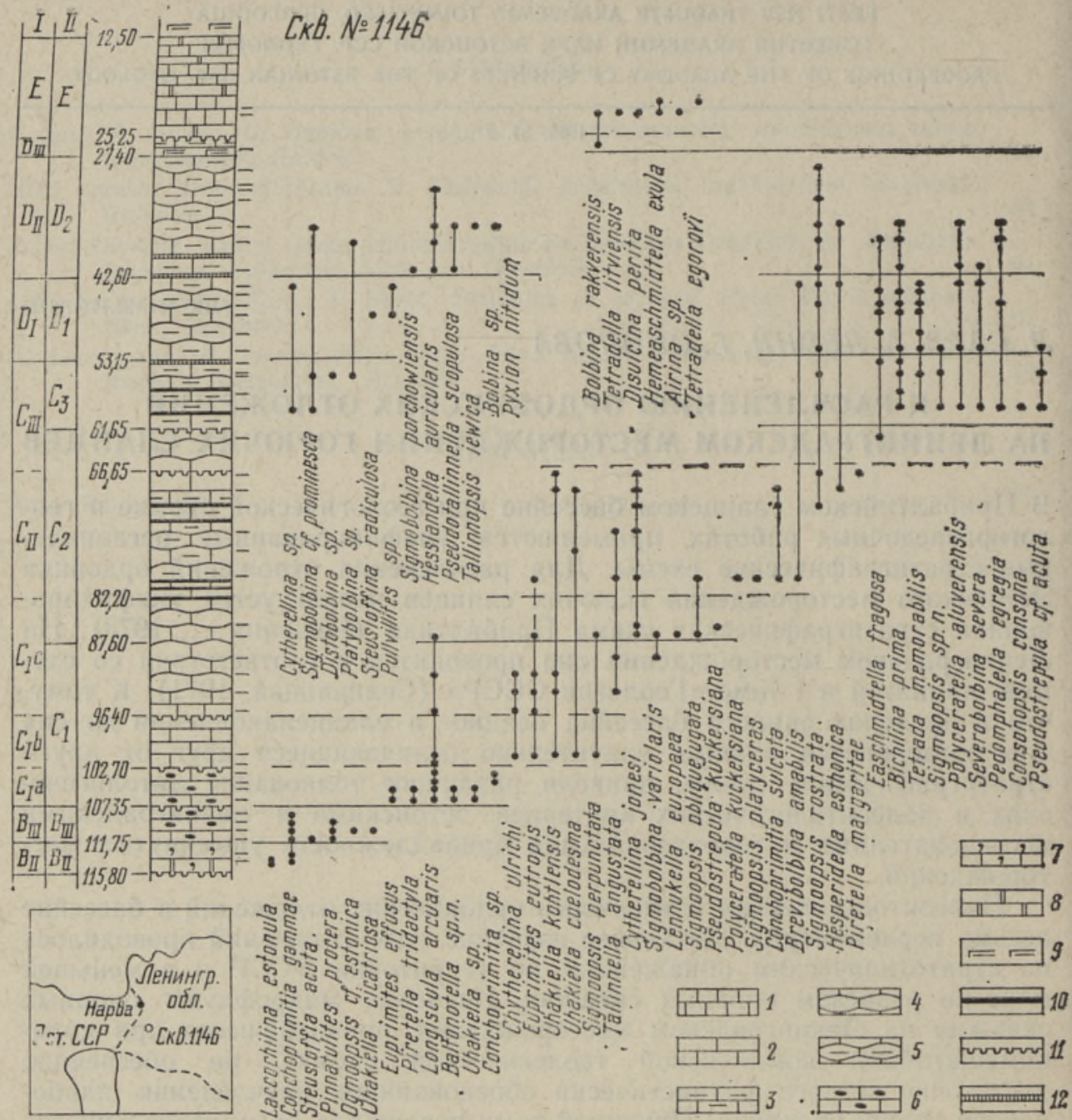

\section{$:::^{\prime}:$}

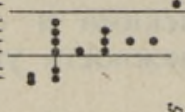

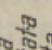

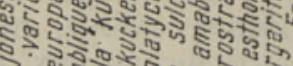

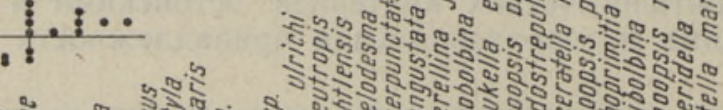

ซรั

5.

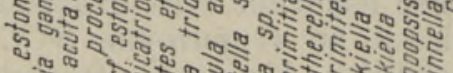
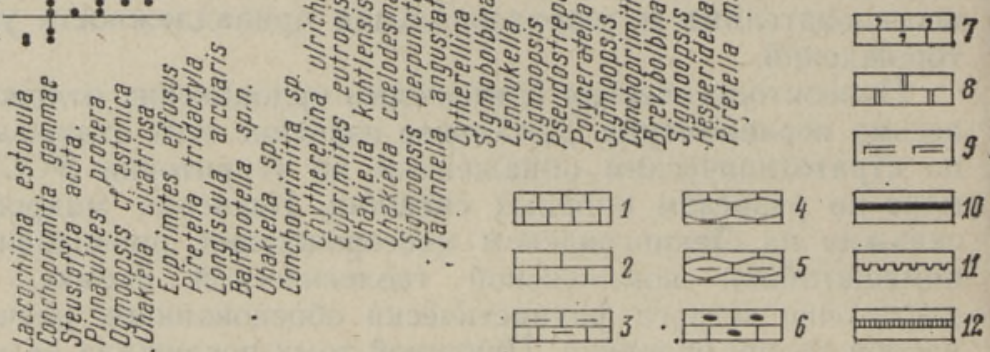

Распространение видов остракод по разрезу разведочной скв. № 1146. I - расчленение разреза по прибалтийской схеме. Горизонты: $B_{\mathrm{II}}-$ волховский, $B_{\mathrm{III}}-$ кундаский, $C_{\mathrm{I}} a-$ азериский, $C_{\mathrm{I}} b-$ ласнамягиский, $C_{\mathrm{I}} c-$ ухакуский, $C_{\mathrm{II}}-$ кукрузеский, $C_{\mathrm{III}}$ - идаверескнй, $D_{\mathrm{I}}$ - йыхвиский, $D_{\mathrm{II}}$ - кейлаский, $D_{\mathrm{III}}-$ оандуский, $E-$ раквереский. II - расчленение разреза по ленинградской схеме. Горизонты: $B_{\text {II }}$ волховский, $B_{\text {III }}$ - кундаский, $C_{1}$ - таллинский, $C_{2}-$ кукерскнй, $C_{3}-$ ндавереский, $D_{1}-$ хревнцкий, $D_{2}-$ кегельский, $E-$ везенбергскнй. Известняки: 1 - афанитовый, 2 - детритовый, 3 - детритовый глинистый, 4 - детритовый комковатый, 5 - комковатый глинистый, 6 - оолнтовый, 7 - глауконнтовый, 8 - доломит, 9 - мергель глинистый, 10 - кукерсит, 11 - поверхность перерыва, 12 прослой метабентонита.

№ 1146 изучались нами по 60 образцам, примерно 15 из которых оказались пустыми из-за доломитизации пород. Распространение обнаруженных видов представлено на рисунке.

Палеогеографически ордовикские отложения на территории Эстонского и Ленинградского месторождений горючих сланцев принадлежат Эстонской зоне Прибалтийского палеогеографического региона (Мянниль, 1966), который характеризуется высокой эндемичностью фауны, особенно хорошо выраженной у таких групп, как трилобиты, остракоды, иглокожие и брахиоподы. Остракоды в этой зоне составляют сменяющие друг друга во времени родовые и видовые ассоциации 
(Сарв, 1959, 1968). Самая древняя ассоциация характеризует нижнеордовикские отложения, в том числе волховский и кундаский горизонты. Последующая среднеордовикская ассоциация встречается в азериском, ласнамягиском, ухакуском и кукрузеском горизонтах. Своеобразная ассоциация отмечена в идавереском, йыхвиском и кейласком горизонтах. Элементы верхнеордовикской ассоциации остракод появляются начиная с оандуского и раквереского горизонтов, а значительное обновление ассоциации намечается в отложениях набалаского горизонта. Примерно такая же закономерность прослеживается в разрезе скважины № 1146, в котором установлено около 60 видов остракод.

Самые древние остракоды в разрезах Северной Эстонии известны из глауконитовых известняков волховского горизонта. Характерными элементами этого довольно богатого комплекса являются Rigidella mitis (Öpik), Ogmoopsis bocki (Öpik), Protallinella grewingki (Bock), Laccochilina estonula Öpik, Conchoprimitia gammae Öpik. Последние два вида имеются и в рассматриваемом разрезе.

Видовой состав остракод кундаского горизонта в разрезах Әстонии достигает 40. Руководящими для горизонта считаются Pinnatulites procera (Kummerow), Uhakiella cicatriosa Sarv, Steusloffia acuta (Krause), Ogmoopsis variabilis Sarv, O. estonica Sarv. Почти все они встречаются в разрезе скв. № 1146, что подтверждает реальность выделения горизонта в Ленинградской области.

Азериский горизонт в области выходов беден остракодами, но в более южных разрезах встречаются Chilobolbina lativelata Jaanusson, Piretella tridactyla Jaanusson, Euprimites effusus Jaanusson, Longiscula arcuaris Neckaja. Вышележащий ласнамягиский горизонт характеризуется присутствием Steusloffia linnarssoni (Krause), Tallinnella marchica (Krause). Здесь появляются Sigmoopsis perpunctata (Öpik), Uhakiella coelodesma Öpik, Euprimites eutropis (Opik). Последние три вида более часто встречаются в вышележащем ухакуском горизонте, где к ним добавляются Uhakiella pumila Öpik, Tallinnella angustata (Krause), Polyceratella kuckersiana (Bonnema), Lennukella europaea (Öpik).

Отложения азериского, ласнамягиского и низов ухакуского горизонтов по схеме для Ленинградской области охватывает таллинский горизонт. Однако эта часть разреза скв. № 1146 легко поддается более подробному расчленению. Низы интервала на глубине $102,70-107,35$ м уже по макролитологическим признакам сопоставимы с отложениями азериского горизонта в Северной Эстонии, такой вывод подтверждается присутствием Piretella tridactyla и Euprimites effusus. Нижнюю границу ласнамягиского горизонта обозначает появление таких видов, как Euprimites eutropis, Uhakiella coelodesma, U. kohtlensis, Sigmoopsis perpunctata. Верхняя граница ласнамягиского горизонта по остракодам нечеткая, но несколько выше этого уровня появляется Tallinnella angustata - характерный вид для вышележащего ухакуского горизонта. На глубине 87,60 м, принятой в качестве верхней границы таллинского горизонта, остракоды существенных изменений не испытывают. Появляющиеся выше этого уровня Cytherellina jonesi Bonnema, Lennukella europaea Opik, Sigmoopsis obliquejugata (Schmidt) и Polyceratella kuckersiana (Bonnema) в разрезах Северной Эстонии широко распространены начиная с низов ухакуского горизонта. В последнем районе в качестве границы между ухакуским и кукрузеским горизонтами принята подошва промпачки горючих сланцев, которая в некоторой степени вырисовывается и в рассматриваемом разрезе: этот уровень не пересекают Sigmoopsis perpunctata и Lennukella europaea, а выше его появляется Brevibolbina amabilis (Neckaja) - характерный вид вышележащих отложений.

Кукрузеский горизонт в стратотипическом регионе характеризуется 
очень богатым комплексом остракод (более 60 видов), из которых наиболее характерными для горизонта являются Uhakiella kohtlensis Öpik, Tallinnopsis perplana (Neckaja), Sigmoopsis platyceras (Öpik), Poly. ceratella bicornis (Neckaja), Primitiella molli (Bonnema), Conchoprimitia sulcata (Krause). Этот комплекс видов тесно связан с комплексом видов нижележащего ухакуского горизонта.

В разрезе скв. 1146 сланцевая залежь фаунистически не изучалась. В остальной части кукрузеского горизонта найдено небольшое количество видов, среди них Brevibolbina amabilis, Sigmoopsis platyceras, Conchoprimitia sulcata и другие переходящие в основном из нижележащих отложений виды, которые исчезают на верхней границе горизонта. Это обстоятельство, а также макролитологические особенности пород подтверждают положение верхней границы горизонта на глубине 66,65 м.

Идавереский горизонт в стратотипическом регионе (пос. Хальяла, ЭССР) состоит из двух подгоризонтов. Нижний подгоризонт $\left(\mathrm{C}_{\mathrm{III}} \alpha\right)$ представлен детритовыми известняками мощностью до 1,8 м, в которых есть редкие представители новой, идавереско-йыхвиско-кейлаской ассоциации остракод: Bichilina prima Sarv, Tetrada memorabilis (Neckaja), Easchmidtella fragosa (Neckaja). В рассматриваемом разрезе этому подгоризонту, вероятно, соответствует интервал 61,6566,65 м, где впервые появляется Easchmidtella fragosa. По ленинградской схеме этот интервал рассматривался в составе кукерского горизонта. Верхний подгоризонт идавереского горизонта в стратотипическом регионе характеризуется уже довольно богатым комплексом, где наряду с перечисленными выше видами распространены Severobolbina severa (Sarv), Polyceratella aluverensis Sarv, Sigmoopsis sp. n., Steusloffina radiculosa Neckaja и другие. В разрезе скв. № 1146 этот комплекс появляется в интервале 53,15-61,65 м, который следует рассматривать в качестве верхнего подгоризонта идавереского горизонта ( $\mathrm{C}_{\text {III }} \beta$, шундоровские слои).

Позднеидавереский и йыхвиский комплексы остракод в стратотипическом регионе очень близки друг другу. Общими видами в интервале $42,60-61,65$ м характеризуются и отложения верхнего подгоризонта идавереского и йыхвиского горизонтов в разрезе скв. № 1146. Большинство видов этого комплекса встречается еще в интервале $27,40-42,60$ м, где отсутствуют характерные для кейлаского горизонта виды Bolbina major (Krause), Tallinnopsis ovalis (Sarv), Pseudostrepula estona Sarv. При этом отсутствуют и типичные представители ндавереско-йыхвиского комплекса Tetrada memorabilis, Sigmoopsis sp. n., Steusloffina radiculosa, что позволяет рассматривать этот интервал в качестве кейлаского горизонта.

По литологии отложения в интервале $25,25-27,40$ м следует включить в оандуский горизонт. Из-за доломитизации пород в них установлен только Bolbina rakverensis Sarv, отсутствуют другие представители новой - верхнеордовикской ассоциации остракод во главе с Klimphores minimus (Sarv). Четко выделяются и отложения раквереского горизонта в интервале $12,50-25,25$ м, в низах которого имеются довольно характерные для этого горизонта Hemeaschmidtella exula Schallreuter, Tetradella egorovi Neckaja, Airina sp.

По ленинградской схеме оандуский и раквереский горизонты объединены в везенбергский горизонт.

Приведенные выше данные указывают на перспективность применения остракод как одного из весьма существенных элементов фауны для обоснования расчленения ордовикских отложений на Ленинградском месторождении горючих сланцев. По остракодам четко выделяются волховский, кундаский, азериский, ухакуский и кукрузеский 
горизонты, довольно хорошо расчленяются и остальные части разреза.

Тем самым подтверждена возможность применения единой стратиграфической схемы для всего Прибалтийского сланцевого бассейна.

\section{ЛИТЕРАТУ РА}

Мянниль P. М. Вопросы сопоставления ордовикских отложеннй Эстонии и Ленинградской области. - Тр. Ин-та геол. АН ЭССР, 1963, 13, 3-40.

Мянниль Р. М. История развития Балтийского бассейна в ордовике. Таллин, 1966.

Решения Межведомственного регионального стратиграфического совещания по разработке унифицированных стратиграфических схем Прибалтики 1976 г. Л., 1978.

Сарв Л. Остракоды ордовика Эстонской ССР. - Тр. Ин-та геол. АН ӨССР, 1959, 4.

Сарв Л. И. Развитие ордовикских остракод Прибалтики. - В кн.: Проблемы палеонтологии. М., 1968, 89-96.

Селиванова В. А. Ордовикская система, - В кн.: Геология СССР, т. I. Ленинградская, Псковская и Новгородская области. М., 1971, 127-173.
Институт геологии
Академии наук Эстонской ССР
Поступила в редакцию
19/I 1984

\section{Эстонский филиал Ннститута горного дела \\ им. А. А. Скочинского}

L. SARV, A. LEVIN, G. ONOLOVA

\section{LENINGRADI POLLEVKIVIMAARDLA ORDOVIITSIUMI SETETE LIIGESTAMISEST}

Balti põlevkivibasseini piires liigestatakse ordoviitsiumi kivimeid erinevate stratigraafiliste skeemide järgi, kusjuures Eesti pōlevkivimaardla puhul kasutatavad üksused erinevad tunduvalt Leningradi põlevkivimaardlal kasutatavatest üksustest oma nimetuse, mahu ja piiride asendi poolest. Basseini piires tehtavatel otsimis- ja luuretöödel kasutatakse läbilōigete korreleerimiseks mitmesuguseid litoloogilisi tunnuseid.

Stratigraafilisele liigestusele mikropaleontoloogilise pöhjenduse saamiseks uuriti Leningradi põlevkivimaardla lääneossa rajatud puuraugu nr. 1146 alam- ja keskordoviitsiumi ostrakoode. Tehti kindlaks 60 liigi levik, mille pōhjal osutus võimalikuks täpsustada selle läbilōike liigestust, kasutades Baltikumi unifitseeritud stratigraafilise skeemi üksusi.

\section{SARV, A. LEVIN, G. ONOLOVA}

\section{ORDOVICIAN STRATIGRAPHY IN THE LENINGRAD OIL SHALE DEPOSIT}

Within the Baltic oil shale basin, the Ordovician deposits are subdivided according to different stratigraphical schemes. The stratigraphic units of the Estonian oil shale deposit differ considerably from those in use for the Leningrad oil shale deposit in respect to their names, volumes and the position of the boundaries. During the research and prospecting work carried out in the basin, the sections were correlated on the basis of various lithological features.

Lower and Middle Ordovician ostracodes from the boring N 1146 of the western part of the Leningrad oil shale deposit were studied in order to obtain a micropaleontological justification for such a stratigraphical subdivision. The distribution of 60 species was ascertained, which enabled to define the subdivision of that section using the units of a unified stratigraphical scheme elaborated for the East Baltic. 